\title{
Rapid Manufacturing of Polyethylene Parts With Controlled Pore Size Gradients Using Selective Laser Sintering
}

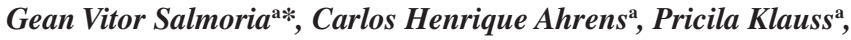 \\ Rodrigo Acacio Paggi ${ }^{a}$, Rafael Galet Oliveira ${ }^{\mathrm{a}}$, Alexandre Lago ${ }^{\mathrm{b}}$ \\ ${ }^{a}$ Laboratorio CIMJECT, Departamento de Engenharia Mecanica, \\ Universidade Federal de Santa Catarina, Campus Universitario Trindade, \\ 88040-200, Floriaonópolis - SC, Brazil \\ ${ }^{\mathrm{b}}$ LABMAT, Departamento de Engenharia Mecânica, Universidade Federal de Santa Catarina, \\ 88040-900, Florianópolis - SC, Brazil
}

Received: March 14, 2007; Revised: June 13, 2007

\begin{abstract}
In this study HDPE specimens were fabricated by selective laser sintering using different particle sizes to obtain controlled variations in the porosity. Electron microscopy, density measurements and mechanical analyses were conducted for the characterization of the specimens. Parts with controlled pore gradients were also manufactured and characterized. The specimens with larger particle sizes had a high sintering degree and a significant level of close pores, as shown by microscopy and density analyses. However, the mechanical properties of specimens prepared with large particles had low values due to the limited density of union points, i.e., low neck number/area. HDPE parts with pore gradients were prepared by selective laser sintering demonstrating that this technique can be used to easily control the structure and the properties of the parts manufactured. This technology may have applications in areas such as drug delivery devices and scaffolds for tissue engineering.
\end{abstract}

Keywords: HDPE parts, pore gradients, selective laser sintering

\section{Introduction}

Rapid manufacturing technologies include a group of fabrication processes through which complex geometries can be built layer by layer, with controlled structures, such as those found in porous thermal systems and bone tissue $e^{1-8}$. In selective laser sintering (SLS), objects are built layer by layer using infrared laser beams to process powder materials. The selective laser sintering process can be used to manufacture parts with metals, ceramics or polymer powders.

The structure and properties of the parts to be manufactured by selective laser sintering should be considered according to their application. The level of control over the microstructure of the SLS parts depends on the process parameters, particularly the powder properties $^{1-2}$, since these can influence other parameters. Particle shape and size distribution influences the powder packing density, while the melting flow behavior and the thermal stability define the laser power and scan speed ${ }^{1,2,14}$.

The use of polymeric materials in the SLS process offers some advantages over metallic and ceramic materials, which are related to the low processing temperatures, melting flow control and high corrosion resistance. However, the variety of commercial polymeric materials available for the SLS process is restricted and this reduces the options available during material selection for the manufacturing of particular parts. The use of non-commercially available polymers and mixtures of polymers can increase the range of properties and applications of the SLS parts ${ }^{9-14}$.

A previous study evaluated the use of the selective laser sintering process for the rapid manufacturing of polyethylene, polyamide and hydroxyapatite composites with potential application in tissue engineering ${ }^{14}$. Composites of polyamide and polyethylene with hydroxyapatite were prepared in SLS apparatus, adjusting the process parameters according to the desired structure and properties. Different structures were produced with controlled porosity (55 to 35\%) and interconnected pores from 50 to $150 \mu \mathrm{m}$, depending on the process parameters and hydroxyapatite content. The possibility to obtain controlled structures and properties using the SLS process can improve the development of new applications in tissue engineering.

In the tissue engineering field, scaffold structures have been the focus of research involving human tissue regeneration. The development of materials and manufacturing techniques to efficiently produce scaffolds with controlled composition, porosity and properties is of great interest in the drug delivery and tissue regeneration areas ${ }^{13-17}$. Polymers with different particle sizes can be used to obtain functionally graded scaffolds through SLS with controlled structures and properties by selecting the particle size for specific regions. This study investigates the fabrication by SLS of HDPE specimens with different particle sizes to obtain variations in the porosity. The specimens were characterized by electron microscopy, porosity measurements and mechanical analyses. Parts with pore size gradients were also constructed and characterized.

\section{Materials and Methods}

The powder polymer used in this study was high density polyethylene HDPE, HD7555 Ipiranga, with a melting temperature (Tm) of $127.7^{\circ} \mathrm{C}$ (according to differential scanning calorimetry). The particle size ranges used were: 106-125; 150-212 and 212-380 $\mu \mathrm{m}$.

The HDPE specimens were prepared by SLS with $35 \times 5 \times 1.4 \mathrm{~mm}$ size. The specimens with particle sizes of 106-125 $\mu \mathrm{m}$ and $150-212 \mu \mathrm{m}$ were built with $200 \mu \mathrm{m}$ layers. The specimens with particle size 212-380 $\mu \mathrm{m}$ were built with $400 \mu \mathrm{m}$ layers. The selective laser sintered specimens were produced with $0.44 \mathrm{~J} . \mathrm{mm}^{-2}$ of density energy. The chamber temperature was $95{ }^{\circ} \mathrm{C}$ and laser scan speed was $44.5 \mathrm{~mm} / \mathrm{s}$.

The morphology of the specimens was examined with a scanning electron microscope (SEM), Phillips XL30. The specimen surfaces 
after the SLS process, and the cryogenic fracture surface and flexural fracture surface of the samples were investigated. The specimens were coated with gold in a Bal -Tec Sputter Coater SCD005.

The apparent density was obtained in a pycnometer of $50 \mathrm{~cm}^{3}$. The average value was obtained from four samples with $35 \times 5 \times 1.4 \mathrm{~mm}$ size. The time of immersion in iso-propanol was four hours. The volumetric density was calculated using the size and mass of the specimens.

The specimens were tested in single cantilever mode using a dynamic mechanical analyzer, DMA Q800. The samples used

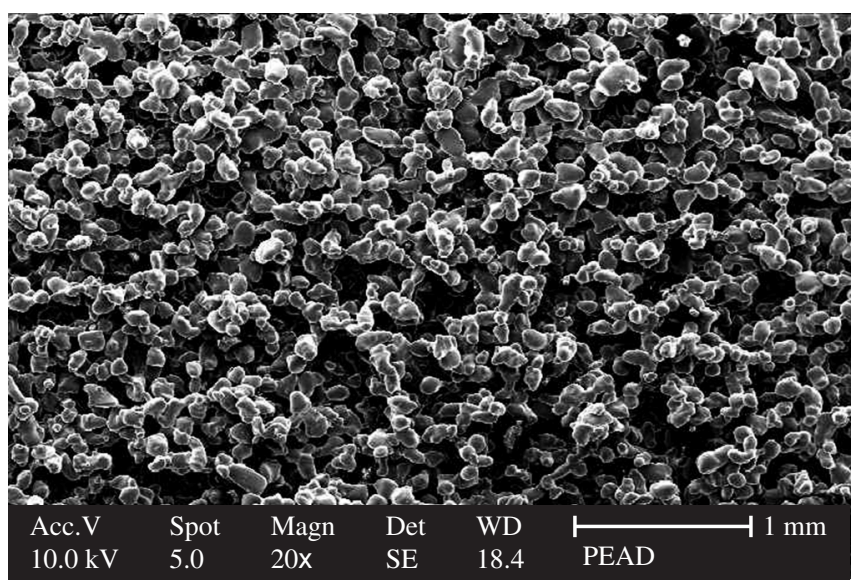

$106-125 \mu \mathrm{m}$

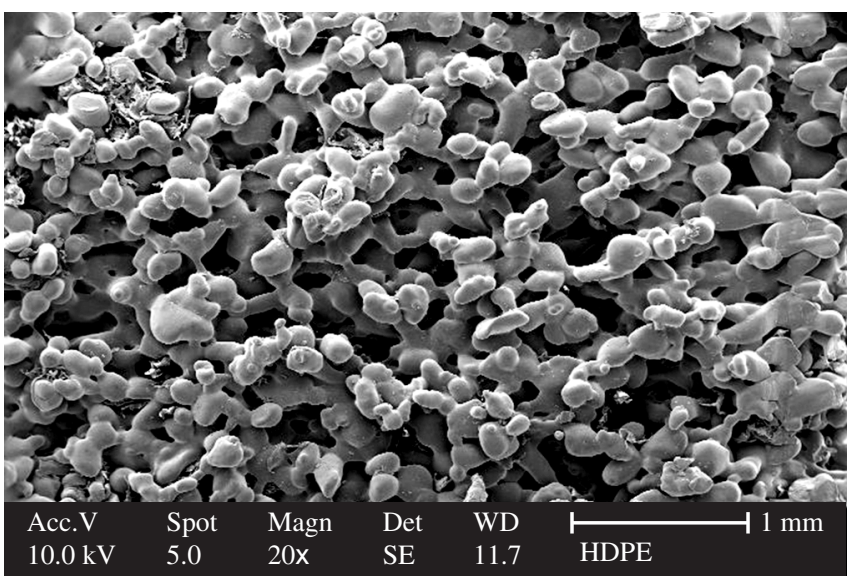

$150-212 \mu \mathrm{m}$

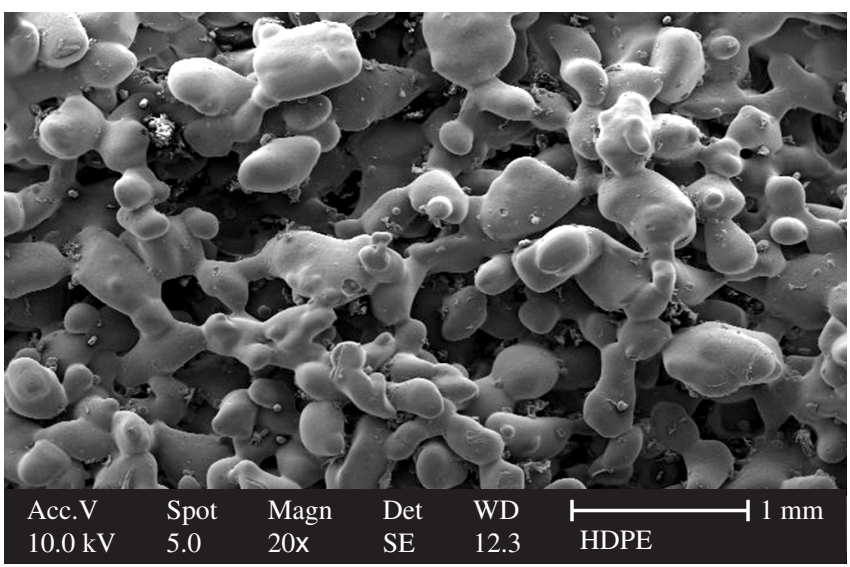

$212-380 \mu \mathrm{m}$ had $18 \mathrm{~mm}$ length, $5 \mathrm{~mm}$ width and a thickness between 1.37 and $1.47 \mathrm{~mm}$. The stress versus strain curves were obtained at $25^{\circ} \mathrm{C}$ and $1 \mathrm{~mm} / \mathrm{min}$ strain rate.

\section{Results and Discussion}

Figure 1 shows the micrographs of the HDPE specimen surface and its cryogenic fracture. The SEM analysis showed that the sintered specimens with particle sizes of 106-125 and 150-212 $\mu \mathrm{m}$ had

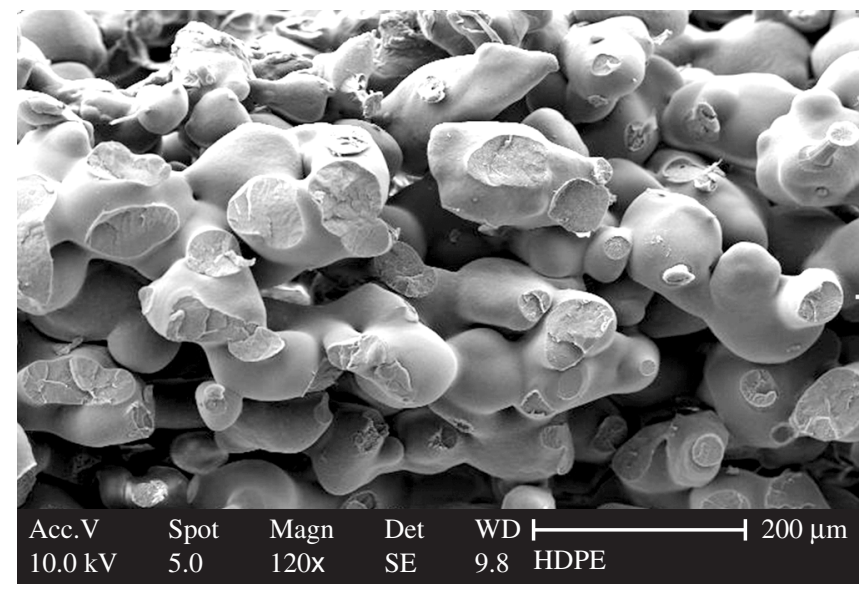

$106-125 \mu \mathrm{m}$

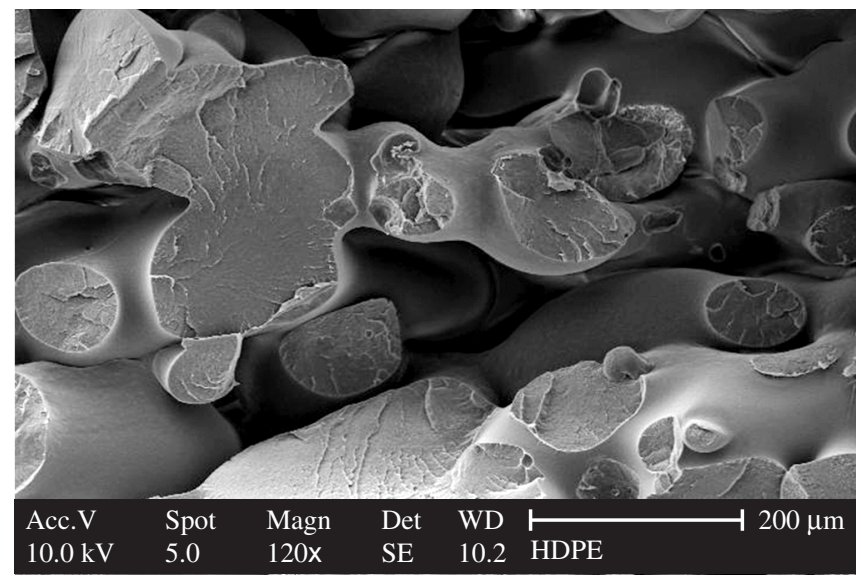

$150-212 \mu \mathrm{m}$

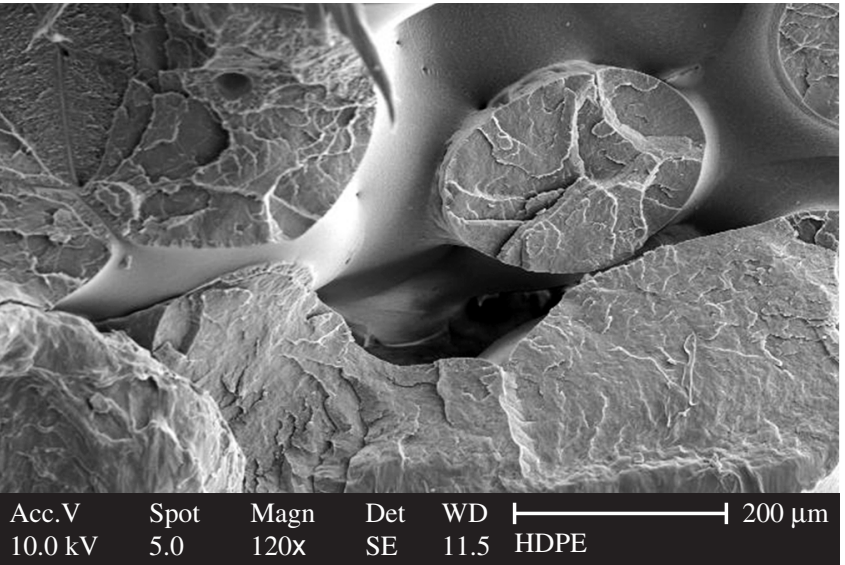

$212-380 \mu \mathrm{m}$

Figure 1. Micrographs of HDPE specimens surface (left) and its cryogenic fracture (right). 
interconnected pores distributed throughout their structures. The specimens prepared with a particle size of 212-380 $\mu \mathrm{m}$ showed irregularities in their structure, probably due to difficulties encountered in the deposition process during the SLS.

The sizes of the pores observed in the specimen micro-structures were a function of the particle size used in the preparation of these specimens. The specimens with particle sizes of 106-125, 150-212 and 212-380 $\mu \mathrm{m}$ had average pore sizes of 200,300 and $500 \mu \mathrm{m}$, respectively. The micrographs of the cryogenic fracture surfaces showed that the particles are well united by an intense neck formation in all specimens. The process conditions used in the specimen preparation resulted in micro-structures with a high sintering degree.

Table 1 gives the theoretical, volumetric and apparent density values for the HDPE specimens prepared with different particle sizes. The volumetric densities of the HDPE specimens were $0.512,0.560$ and 0.490 for particle sizes of 106-125, 150-212 and $212-380 \mu \mathrm{m}$, respectively, which indicates a significant level of porosity $(\approx 35 \%)$. The apparent densities of the HDPE specimens were $0.774,0.749$ and 0.729 for particle sizes of 106-125, 150-212 and $212-380 \mu \mathrm{m}$, respectively, which indicates that the specimens with larger particle sizes had lower open porosities, i.e., higher densification due to the lower heating dissipation by conduction and convection mechanisms during the laser sinterization.

Figure 2 shows stress versus strain curves for the specimens fabricated with different particle sizes. The $106-125 \mu \mathrm{m}$ particle size specimens had a higher average elastic modulus and tensile strength than the $212-380 \mu \mathrm{m}$ particle size specimens, as expected due to the degree of sintering and the number of necks per area. The results

Table 1. Values of theoretic, volumetric and apparent density of the HDPE specimens prepared with different particles size.

\begin{tabular}{cccc}
\hline $\begin{array}{c}\text { Particle size } \\
(\mu \mathrm{m})\end{array}$ & $\begin{array}{c}\rho_{\text {theoretic }} \\
\left(\mathrm{g} \cdot \mathrm{cm}^{-3}\right)\end{array}$ & $\begin{array}{c}\rho_{\text {volumetric }} \\
\left(\mathrm{g} . \mathrm{cm}^{-3}\right)\end{array}$ & $\begin{array}{c}\rho_{\text {apparent }} \\
\left(\mathrm{g} . \mathrm{cm}^{-3}\right)\end{array}$ \\
\hline $106-125$ & 0.950 & 0.512 & 0.774 \\
$150-212$ & 0.950 & 0.560 & 0.749 \\
$212-380$ & 0.950 & 0.490 & 0.729 \\
\hline
\end{tabular}

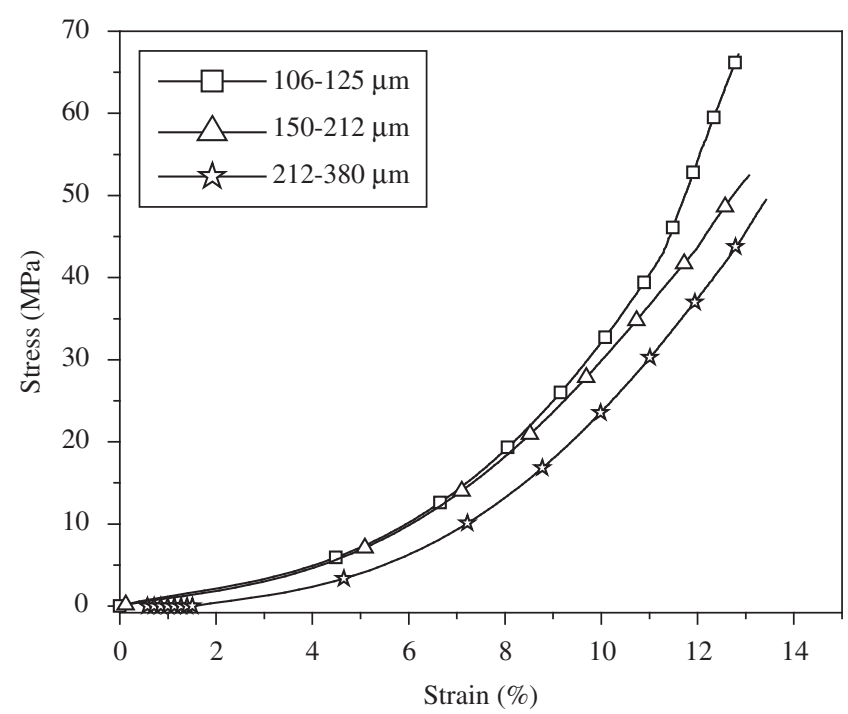

Figure 2. Stress versus strain curves for the HDPE specimens prepared with different particles size. suggest that the strength of the samples decreased with the increase in particle size. Particles with smaller sizes have a larger superficial contact area, contributing to the particle connections, forming a higher number of the necks per area.

The average value for the Young's modulus decreased from 105.1 to $84.4 \mathrm{MPa}$ from the $106-125 \mu \mathrm{m}$ to the $212-380 \mu \mathrm{m}$ particle size specimens. The 150-212 $\mu \mathrm{m}$ particle size specimens had intermediate values for the Young's modulus. An analogous behavior was observed for tensile strength for all samples studied, as shown in Table 2. On the other hand, the average strain of the 212-380 $\mu \mathrm{m}$ particle size specimens was higher than that of the 106-125 $\mu \mathrm{m}$ particle size specimens.

Figure 3 shows micrographs of the fracture surface at different magnifications after mechanical testing of a $212-380 \mu \mathrm{m}$ particle size

Table 2. Average mechanical properties of the HDPE specimens prepared with different particles size.

\begin{tabular}{cccc}
\hline $\begin{array}{c}\text { Particles size } \\
(\mu \mathrm{m})\end{array}$ & $\begin{array}{c}\text { Elastic modulus } \\
(\mathrm{MPa})\end{array}$ & $\begin{array}{c}\text { Ultimate strength } \\
(\mathrm{MPa})\end{array}$ & $\begin{array}{c}\text { Failure } \\
\text { deformation } \\
(\%)\end{array}$ \\
\hline $106-125$ & 105.1 & 67.19 & 12.95 \\
$150-212$ & 103.6 & 52.44 & 13.07 \\
$212-380$ & 84.4 & 49.47 & 13.42 \\
\hline
\end{tabular}

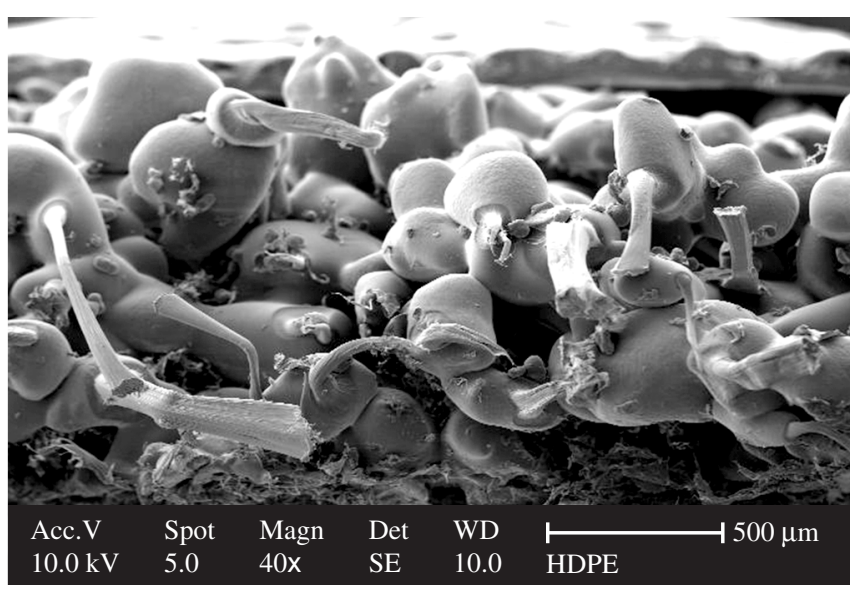

(a)

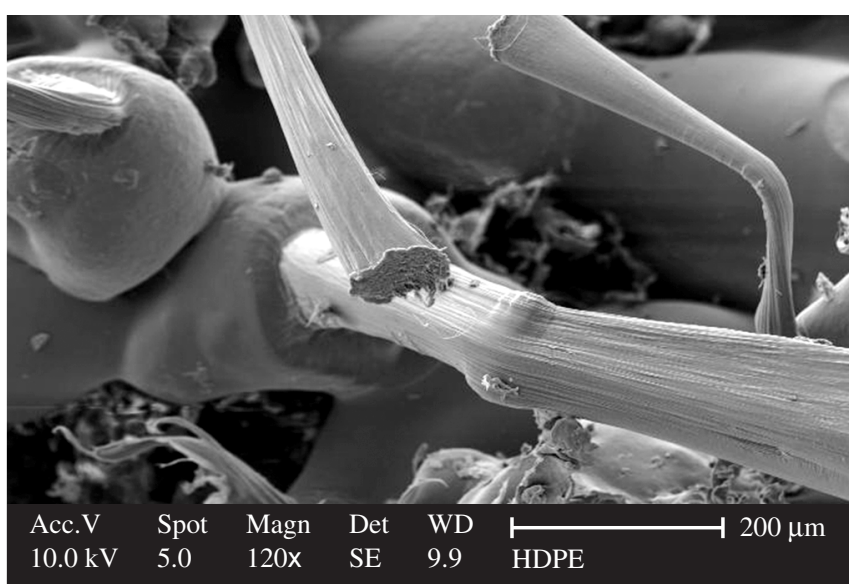

(b)

Figure 3. Fracture surface of the HDPE samples fabricated with particles of $212-380 \mu \mathrm{m}$. 
specimen. We can observe that only a low number of necks per area were formed during the sintering process due to the particle size. An extraction in cross section of the particles was observed close to the fracture surface. The fracture surface micrograph shows characteristic features of ductile failure with plastic deformation, which was observed particularly in the neck regions. Shear and cavitation are evident in the plastic deformation region, suggesting chain slippage as the failure mechanism in this region, where the flaw propagation speed is reduced by the stress release.

Figure 4 shows the part with a pore size gradient (100 up to $500 \mu \mathrm{m}$ ), which was obtained by laser sintering using the processing parameters previously defined. The HDPE part with pore gradients showed an increase in pore size and a decrease in strength as the particle size increased, as observed for individual specimens.

The use of SLS to prepare parts and components with gradients of structures and properties is possible and this can improve the development of applications in new porous material areas, such as thermal systems and bone tissue.

\section{Conclusions}

The characterization of HDPE specimens prepared by SLS using different particle sizes showed that the pore size is a function of the particle size and the sintering degree. The specimens with larger particle size had a higher sintering degree and a significant level of close pores, as shown by microscopy and density analyses. However, the mechanical properties of specimens prepared with larger particles had lower values due to the limited number of union points, i.e., low neck number/area.

HDPE parts with pore gradients were prepared by selective laser sintering demonstrating that this technique can be used to easily control the structure and the properties of the parts manufactured. This technology may have applications in areas such as drug delivery devices and scaffolds to tissue engineering.

\section{Acknowledgments}

The authors would like to acknowledge FAPESC, FINEP, CNPq and CAPES for the financial support.

\section{References}

1. Jacobs PF. Rapid Prototyping and Manufacturing: Fundamentals of Stereolithography, ed. Dearborn-USA: Society of Manufacturing Engineers; 1993.

2. Jacobs PF, From Rapid Prototyping to Rapid Tooling, ed. New York: ASME; 1999.

3. Das S, Hollister SF, Flanagan C, Adewunmi A, Bark K, Chen C, Ramaswamy K, Rose A. Freeform fabrication of Nylon-6 tissue engineering scaffolds, Rapid Prototyping Journal. 2003; 9(1):233-242.

4. Zein I, Hutmacher DW, Tan KC, Teoh SH, Fused deposition modeling of novel scaffold architectures for tissue engineering applications, Biomaterials. 2002; 23:1169-1185.

5. Hur S, Choi K, Lee S, Chang C. Determination of fabricating orientation and packing in SLS process. Journal of Materials Processing Technology. 2001; 112:236-243.

6. King D, Tansey T. Rapid Tooling: selective laser sintering injection tooling. Journal of Materials Processing Technology. 2003; 132:42-48.

7. Gibson I, Shi D. Material Properties and fabrication Parameters in Selective Laser Sintering process. Rapid Prototyping Journal. 1997; 3(4):129-136.
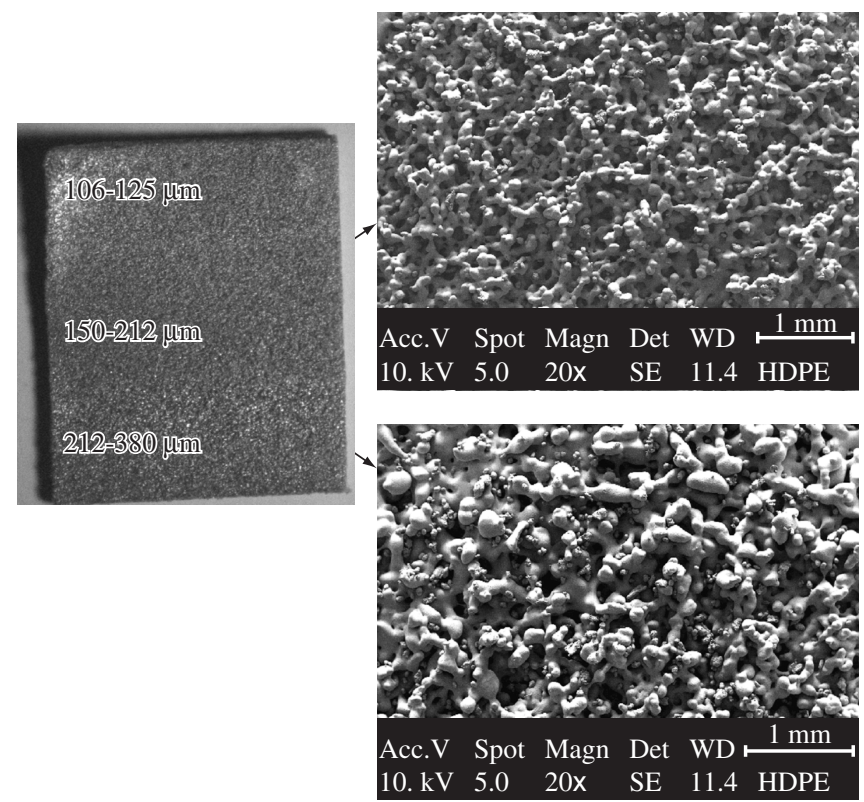

Figure 4. Images of the part with controlled pore size gradients made by the SLS of different particles size (106-125, 150-212 and 212-380 $\mu \mathrm{m})$.

8. Mazzoli A, Moriconi G, Pauri MG, Characterization of an alumina-filled polyamide powder for applications in selective laser sintering. Materials \& Design. 2007; 28:993-1000.

9. Ho HCH, Gibson I, Cheung WL, Effects of energy density on morphology and properties of selective laser sintered polycarbonate. Journal of Materials Processing Technology. 1999; 89:204-210.

10. Kulman C, Leite JL, Alcântara B, Lago A, Salmoria GV, Ahrens CH. "Manufacturing of functionally graded polyamide-graphite composite by selective laser sintering". In: PPS-2004 Americas Regional Meeting Symposia, Florianópolis- SC-Brazil, Nov. 2004, 228 -229.

11. Salmoria GV, Ahrens CH, Leite JL, Lago A, Pires ATN. Microstructural characterization of PA2200/HDPE blends produced by rapid manufacture using selective laser sintering. Brazilian Journal of Morphological Sciences. 2005; 5:402.

12. Ho HCH, Cheung WL, Gibson I. Effects of graphite powder on the laser sintering behaviour of polycarbonate. Rapid Prototyping. 2002; 8(4):233-242.

13. Zheng H, Zhang J, Lu S, Wang S, Xu Z. Effect of core-shell composite particles on the sintering behavior and properties of nano-Al2O3/ polystyrene composite prepared by SLS. Materials Letters. 2006; 60:1219-1223.

14. Dabbas F. Sinterização Seletiva a Laser de Compósitos Poliamida/Hidroxiapatita e Polietileno/Hidroxiapatita com Gradientes Funcionais Aplicáveis em Engenharia Tecidual [published Master Dissertation]. Florianópolis-Brasil: Universidade Federal de Santa Catarina; 2006.

15. Hutmacher DW, Sittinger M, Risbud MV, Scaffold-based tissue engineering: rationale for computer-aided design and solid free-form fabrication systems. Treds in Biotechnology. 2004; 22(7):354-362.

17. Tan K H, Tha C K, Leong K F, Heah C M, Cheang P, Abu M S. Scaffold development using selective laser sintering of polyetheretherketone-hydroxyapatite biocomposite blends. Biomaterials. 2003; 23:3115-3123.

18. Wei G, Ma PX, Structure and properties of nano-hydroxyapatite/polymer composite scaffolds for bone tissue engineering. Biomaterials. 2004; 25:4749-4757. 